\title{
Impact of bacterial activity on turnover of insoluble hydrophobic substrates (phenanthrene and pyrene)-Model simulations for prediction of bioremediation success
}

Rein, Arno; Adam, Iris K.U.; Miltner, Anja; Brumme, Katja; Kästner, Matthias; Trapp, Stefan

Published in:

Journal of Hazardous Materials

Link to article, DOI:

10.1016/j.jhazmat.2015.12.005

Publication date:

2016

Document Version

Peer reviewed version

Link back to DTU Orbit

Citation (APA):

Rein, A., Adam, I. K. U., Miltner, A., Brumme, K., Kästner, M., \& Trapp, S. (2016). Impact of bacterial activity on turnover of insoluble hydrophobic substrates (phenanthrene and pyrene)-Model simulations for prediction of bioremediation success. Journal of Hazardous Materials, 306, 105-114.

https://doi.org/10.1016/j.jhazmat.2015.12.005

\section{General rights}

Copyright and moral rights for the publications made accessible in the public portal are retained by the authors and/or other copyright owners and it is a condition of accessing publications that users recognise and abide by the legal requirements associated with these rights.

- Users may download and print one copy of any publication from the public portal for the purpose of private study or research.

- You may not further distribute the material or use it for any profit-making activity or commercial gain

- You may freely distribute the URL identifying the publication in the public portal 
1 Incomplete, not-final pre-print version. To get the final version see here:

Model simulations and impact of bacterial activity on turnover and bioremediation of insoluble hydrophobic substrates (phenanthrene and pyrene)

7 Arno Rein ${ }^{1, x, a}$, Iris K. U. Adam ${ }^{2, x}$, Anja Miltner ${ }^{2}$, Katja Brumme ${ }^{2}$, Matthias Kästner ${ }^{2,+,}$, 8 Stefan Trapp ${ }^{1,+}$

1) Department of Environmental Engineering, Technical University of Denmark, Miljøvej bd. 113, DK-2800 Kgs. Lyngby, Denmark.

2) UFZ - Helmholtz-Centre for Environmental Research, Department of Environmental Biotechnology, Permoserstr. 15, 04318 Leipzig, Germany.

*) Corresponding author; phone +49341235-1235; fax: +49341235-451235; e-mail: matthias.kaestner@ufz.de

${ }^{x}$ ) both authors contributed equally to this work 80333 Munich, Germany 


\section{Abstract}

Many attempts for bioremediation of polycyclic aromatic hydrocarbon (PAH) contaminated sites failed in the past, but the reasons for this failure are not well understood. Here we apply and improve a model for integrated assessment of mass transfer, biodegradation and residual concentrations for predicting the success of remediation actions. First, we provide growth parameters for Mycobacterium rutilum and $M$. pallens growing on phenanthrene (PHE) or pyrene (PYR) degraded the PAH completely at all investigated concentrations. Maximum metabolic rates $V_{\max }$ and growth rates $\mu$ were similar for the substrates PHE and PYR and for both strains. The investigated Mycobacterium species were not superior in PHE degradation to strains investigated earlier with this method. Real-world degradation scenario simulations including diffusive flux to the microbial cells indicate: that i) bioaugmentation only has a small, short-lived effect; ii) Increasing sorption shifts the remaining PAH to the adsorbed/sequestered PAH pool; iii) mobilizing by solvents or surfactants resulted in a significant decrease of the sequestered $\mathrm{PAH}$, and iv) co-metabolization e.g. by compost addition can contribute significantly to the reduction of $\mathrm{PAH}$, because active biomass is maintained at a high level by the compost. The model therefore is a valuable contribution to the assessment of potential remediation action at PAH-polluted sites.

Keywords: PAH-degradation, mycobacteria, growth, kinetics, modelling, bioremediationoptions. 


\section{Introduction}

Polycyclic aromatic hydrocarbons (PAH) are hydrophobic compounds with two or more condensed benzene rings in their molecular structure [1]. They exhibit high toxicity and cancerogeneity [2]. PAH are metabolised by several bacteria, fungi, algae and also by cytochrome P-450 monooxygenases of higher eukaryotic cells [3], but undergo no or slow decomposition in the environment [4]. Full mineralisation with productive growth is only known for bacteria [5]. However, reports about full mineralisation of $\mathrm{PAH}$ with $>5$ rings are relatively rare [6].

Varying concentrations of PAH occur in coals, crude oils and oil-based products. They are formed during pyrolysis and incomplete combustion of biological material and organic compounds and thus one main source of the anthropogenic formation and emission of PAH is the combustion of fossil fuels in vehicles and for power generation [7]. Due to their properties, $\mathrm{PAH}$ are released during combustion adsorbed to dust and soot particles, and are then more or less globally distributed in the environment [8]. PAH also frequently occur in urban soil environments due to the process of coal gasification in the $19^{\text {th }}$ century [9] leading to the formation of waste tar oils often dumped in open pits at the manufactured gas plant sites. Later with increasing urbanisation the tar oil ponds were solidified with waste coke materials and coal powders that could not be burned in the plants at that time. These widespread contaminations entered focus in the late 1980s and gas works sites or sites where tar oil products were spilled were identified to need technical soil remediation. Many attempts for bioremediation failed without real understanding of the reasons, most probably because $\mathrm{PAH}$ tend to sorb strongly to coal and coke particles or to so-called non-aqueous phase liquids (NAPL) soil [3]. The biodegradation of the hardly water-soluble PAH is typically limited by the diffusive flux to the microbes. Aging or sequestration was considered to lower the bioavailability of these compounds, since sorption to soil gets stronger ( $\mathrm{K}_{d}$ increases) with time and degradation half-times increase with time, resulting in a fraction of persistent compounds [10,11]. 
Recently a modelling approach for integrated mass transfer, biodegradation (parameter determination: $\mathrm{v}_{\max }, \mathrm{K}_{\mathrm{M}}$ and yield) and residual concentration assessment was developed and applied for the turnover of non-water soluble substrates like $\mathrm{PAH}$ under mass transfer limitations $[5,12]$. The model equations imply that below a certain substrate concentration, or more exactly below a certain substrate flux to the microorganisms, bacterial growth ceases and bacterial populations start to decline which in turn leads to non-degraded residues. For the prospective assessment of the turnover of $\mathrm{PAH}$ there is a research gap since only very limited kinetic data for different groups of $\mathrm{PAH}$ degrader bacteria are available. In particular for mycobacteria the knowledge is limited [13] due to the complex cell cycle with formation of cell clusters and aggregates with $\mathrm{PAH}$.

The goal of the present work is to determine and compare growth and affinity parameters for well described phenanthrene (PHE) and pyrene (PYR) degrading mycobacteria on both substrates. In addition, the unified modelling approach for sorption and degradation [5, 12] was improved and applied to prospectively describe the dynamics of the PAH compound turnover for various treatment options for soil at contaminated sites. Simulated treatment options include bioaugmentation measures, the addition of adsorbing amendments for reducing pollutant mobility, the addition of solvents or chelators for increasing pollutant dissolution, as well as measures for stimulating co-metabolism (addition of co-substrates such as compost).

\section{Materials and Methods}

\subsection{Strains and culture conditions.}

For the comparative assessment of degradation kinetics, the well described Mycobacterium rutilum (PHE and PYR degraders) and Mycobacterium pallens (PYR degrader) were chosen as model microorganisms [14] based on their multiple PAH degradation (PHE and PYR), 
growth kinetics in liquid cultures and their origin from different environmental samples (Table 1).

The strains were pre-cultivated on mineral medium (MM) with vitamins (Brunner, DSMZ no. 462) consisting of $\mathrm{Na}_{2} \mathrm{HPO}_{4}$ 2.44.gL $\mathrm{L}^{-1}, \mathrm{KH}_{2} \mathrm{PO}_{4}$ 1.52.gL $\mathrm{L}^{-1},\left(\mathrm{NH}_{4}\right)_{2} \mathrm{SO}_{4} 0.5 \cdot \mathrm{gL}^{-1}, \mathrm{MgSO}_{4} \times 7 \mathrm{H}_{2} \mathrm{O}$ 0.2. $\mathrm{gL}^{-1}, \mathrm{CaCl}_{2} \times 2 \mathrm{H}_{2} \mathrm{O} \quad 0.05 \cdot \mathrm{gL}^{-1}$, trace element solution $\mathrm{SL}-4$ 10. $\mathrm{mLL}^{-1}$ (containing per $\mathrm{L}^{-1}$ : EDTA $0.5 \cdot \mathrm{g}, \mathrm{FeSO}_{4} \times 7 \mathrm{H}_{2} \mathrm{O} 0.2 \cdot \mathrm{g}$ and trace element solution SL-6 $100 \cdot \mathrm{mLL}^{-1}$ [containing per $\mathrm{L}^{-}$ $1 \mathrm{ZnSO}_{4} \times 7 \mathrm{H}_{2} \mathrm{O} \quad 0.1 \cdot \mathrm{g}, \mathrm{MnCl}_{2} \times 4 \mathrm{H}_{2} \mathrm{O} \quad 0.03 \cdot \mathrm{g}, \mathrm{H}_{3} \mathrm{BO}_{3} \quad 0.3 \cdot \mathrm{g}, \mathrm{CoCl}_{2} \times 6 \mathrm{H}_{2} \mathrm{O} \quad 0.2 \cdot \mathrm{g}, \mathrm{CuCl}_{2} \times 2 \mathrm{H}_{2} \mathrm{O}$ $0.01 \cdot \mathrm{g}, \mathrm{NiCl}_{2} \times 6 \mathrm{H}_{2} \mathrm{O}$ 0.02.g, $\mathrm{Na}_{2} \mathrm{MoO}_{4} \times 2 \mathrm{H}_{2} \mathrm{O}$ 0.03.g]) and $2.5 \cdot \mathrm{mLL}^{-1}$ vitamin solution consisting of $\mathrm{p}$-aminobenzoate $10 \cdot \mathrm{mgL}^{-1}$, biotin $2 \cdot \mathrm{mgL}^{-1}$, nicotinic acid $20 \cdot \mathrm{mgL}^{-1}$, thiamine- $\mathrm{HCl} \times 2 \mathrm{H}_{2} \mathrm{O}$ 10. $\mathrm{mgL}^{-1}$, Ca-pantothenate $5 \cdot \mathrm{mgL}^{-1}$, pyridoxamine $50 \cdot \mathrm{mgL}^{-1}$, vitamin $\mathrm{B}_{12} 20 \cdot \mathrm{mgL}^{-1}$ [15]. PHE (98\% purity, Sigma-Aldrich, Saint Louis, USA) or PYR (>96\% purity, Merck Schuchardt, Hohenbrunn, Germany) was provided as a sole source of carbon and energy.

\subsection{Experimental set-up.}

To overcome the inhomogeneities of PAH cultures with total concentrations above water solubility, a 'mini-culture approach' [5] for enabling initially non-limited growth on PAH was developed. Briefly, a set-up of destructively sampled small vials (10.mL with finally $2 \cdot \mathrm{mL}$ culture) containing $1800 \cdot \mu \mathrm{L}$ of MM was applied in which the initially introduced PHE or PYR solution in acetone was evaporated and the remaining PAH microcrystals were allowed to equilibrate with the MM overnight. The acetone was then allowed to fully evaporate while shaking the vials for covering the bottom surface with a PHE or PYR microcrystal layer corresponding to nominal medium concentrations of $10,25,50,100,200$ and $400 \cdot \mathrm{mgL}^{-1}$ (only $100 \cdot \mathrm{mgL}^{-1}$ for pre-cultures) prior to adding the MM. The vessels were inoculated to an initial optical density of 0.01 at $560 \mathrm{~nm}$ by adding $200 \mu$ of a pre-culture under similar medium conditions at the late exponential phase and incubated at $30^{\circ} \mathrm{C}$ at $135 \mathrm{rpm}$. Finally, the vessels were closed with teflon coated butyl rubber septa for cultivation. Each vessel was destructively sampled and analysed at the respective sampling time. The experiment was 
performed in six replicates for each concentration and time for providing two triplicate sets for separate quantification of biomass and PHE or PYR. They were harvested after $0,4,8,12$, 24, 36, 48, and 96.h of incubation for initial 10,25 and $50 \cdot \mathrm{mgL}^{-1} \mathrm{PHE}$ or PYR concentrations and after $0,6,12,24,48,72,96,192$ and $288 \cdot h$ for initial 100,200 and $400 \cdot \mathrm{mgL}^{-1} \mathrm{PHE}$ or PYR conc. for both strains (M. rutilum and M. pallens). The harvested cultures were stored at $-20^{\circ} \mathrm{C}$ until further analysis.

\subsection{Protein analysis.}

For monitoring the growth of the bacteria, we tried to measure the protein photometrically in 96 well plates (BIO-RAD-Protein-Assay, Bio-Rad Laboratories GmbH, München, Germany) as described previously [5]. The protein measurements for both mycobacteria were highly variable due to the cell cycle of these bacteria and due to clustering with the microcrystals (see Supporting Material SM). The optical density at $560 \mathrm{~nm}(O D)$ measured after rigorous shaking of the cultures gave more consistent results than the direct measurement of the microbial protein concentration and was used to monitor bacterial growth in the degradation experiments. Microbial protein concentrations $C_{X}$ were then calculated from $O D$ under consideration of the microcrystals of the chemicals (PHE or PYR) in solution using the conversion factor $f_{C X}$ (see SM, Figures SM2 and SM3).

\subsection{PAH analysis.}

For tracking the $\mathrm{PAH}$ consumption the mini cultures were extracted two times with $2 \mathrm{ml}$ of hexane with fluorene as internal standard and analyzed by GC-MS as described previously [5]. Briefly, PYR and PHE were quantified by means of a gas chromatograph equipped with a BPX5 column coupled to a mass spectrometer (5975C, Agilent Technologies). The GC oven temperature was programmed to initial $40^{\circ} \mathrm{C}(2 \mathrm{~min}$ hold $)$, then heat to $180^{\circ} \mathrm{C}(2 \mathrm{~min}$ hold $)$ at $40^{\circ} \mathrm{Cmin}^{-1}$, to $240^{\circ} \mathrm{C}(2 \mathrm{~min}$ hold $)$ at $5^{\circ} \mathrm{Cmin}^{-1}$ and to a final temperature of $300^{\circ} \mathrm{C}$ (5 min hold $)$ at $15^{\circ} \mathrm{Cmin}^{-1}$ with a helium flow of $1.5 \mathrm{ml} \mathrm{min}{ }^{-1}$. The injector was set to $280^{\circ} \mathrm{C}$. The MS was operated in the electron impact ionization mode at $70 \mathrm{eV}$. The source temperature was set to 
$148230^{\circ} \mathrm{C}$, the quadrupole temperature to $150^{\circ} \mathrm{C}$. Full scans were acquired in the $\mathrm{m} / \mathrm{z}$ range 40 149500.

150

151

152

153

154

155

157

158

159

$\frac{d m_{M}}{d t}=\frac{v_{\max } \times C_{W}}{K_{M}+C_{W}} \times X=v \times X$

$\frac{d X}{d t}=\left(\frac{d m_{M}}{d t}-X \times r\right) \times Y$

$\frac{d m_{W}}{d t}=+\frac{d m_{p h}}{d t}-\frac{d m_{M}}{d t}$
161

162

where Eq. (1) describes dissolution flux (mass from organic PAH phase $m_{p h}$ ), Eq. (2) metabolic flux ( $m_{M}$ is metabolized PAH mass), Eq. (3) microbial growth (microbial mass $X$ ) and Eq. (4) change of PAH mass $m_{W}$ in water. $S$ is water solubility $\left(\mathrm{mgL}^{-1}\right)$, concentration $C$ is $m / V$, with mass $m$ (g or $\mathrm{mg}$ ) and volume $V\left(\mathrm{~L}\right.$ or $\left.\mathrm{m}^{3}\right) . C_{W}\left(\mathrm{mgL}^{-1}\right)$ is freely dissolved concentration, the total $\mathrm{PAH}$ concentration in suspension is $C_{\text {Sus }}=\left(m_{p h}+m_{W}\right) / V$. The equation system includes degradation (Monod kinetics) parameters $v_{\max }, K_{M}, Y, b$, maintenance $r$ is given as $r=b / Y$ (parameter names and units see Table 2). Parameters for dissolution kinetics are permeability or mass transfer coefficient $P\left(\mathrm{md}^{-1}\right)$ and surface area of PAH phase 
$A_{p h}\left(\mathrm{~m}^{2}\right)$, which is calculated from $m_{p h}$ and correction factor $f_{A}$ for deviations from cubic geometry (details see SM).

Lag phases, which occurred in most of the experiments, were considered by determining a time $t_{\text {lag }}$ by which microbial degradation is delayed, i.e. metabolic flux $\mathrm{d} m_{N} / \mathrm{d} t$ was set to zero for times $t \leq t_{\text {lag. }}$. Eq. (2) modifies accordingly by multiplying metabolic flux $\mathrm{d} m_{N} / \mathrm{d} t$ with $f_{\text {tlag }}$ which is either 1 or 0 ,

$$
f_{\text {tlag }}=\left\{\begin{array}{lll}
0 & \text { if } & t \leq t_{\text {lag }} \\
1 & \text { if } & t>t_{\text {lag }}
\end{array}\right.
$$

and this was realized within MATLAB ${ }^{\text {TM }}$ by using a modified Heaviside function [16].

The considered model approach is improved and simplified compared to our previous study [5], as kinetic fitting parameters have been reduced from 7 to 6 (the four Monod parameters, $t_{\text {lag }}$ and $\left.f_{A}\right)$. Moreover, $f_{A}$ is the only fitting parameter for dissolution, and $t_{\text {lag }}$ only evokes a delay in the onset of degradation. This simplicity is an advantage and further development compared to the approach in Adam et al. [5] where two fitting parameters for dissolution kinetics $\left(f_{A, 0}\right.$ and $\left.k_{a g g}\right)$ were applied and high values of the fitting parameter for the lag phase (factor $f_{\text {inh,corr) }}$ took influence over the entire duration of the experiment, not only during the time of the lag phase. The parameter $t_{\text {lag }}$ is easy to determine (adjusted for the individual experiments), and different $f_{A}$ can be considered for obtaining model curves at best estimate as well as minimum and maximum estimates for the range of reasonable curve fits. Applying $t_{\text {lag }}$ (Eq. 5) needs only one parameter and results in a sudden "step-like" change (zero metabolic flux during the lag phase). As some observations may suggest a gradual onset of PAH degradation, rather than a sudden start, additional model studies were done with $f_{\text {tlag }}$ approaching 1 exponentially within $t_{\text {lag }}$ (improving only some curve fits slightly; results not shown).

All differential equations were solved numerically, both by an Euler one-step solution scheme realized as Microsoft-Excel ${ }^{\mathrm{TM}}$-spreadsheet and by the ODE45-solver (Runge-Kutta-scheme 
with variable step size) within MATLAB ${ }^{\mathrm{TM}}{ }_{-} \mathrm{R} 2014 \mathrm{~b}$. The correct implementation of the model was quality-controlled by comparing both numerical solutions and by verification against analytical (steady-state) solutions offered by the Best equation. The Best equation balances diffusive flux to the bacterium with metabolic flux in a steady state, thus considering equal and temporally constant dissolution and degradation kinetics (for details see [17]). These conditions were mimicked with the dynamic model (solving Eq. 1 to 5 numerically) by starting with initial conditions at steady-state, where identical results were obtained.

\subsection{Determination of kinetic parameters.}

Bacterial growth and yield parameters were fitted by inverse modeling, i.e. least-square fitting with manual adjustment of parameters, and parameter sensitivity was investigated. Details on the fitting procedure are given in the following and the SM (Section 3). Statistical data on the curve fits (root-mean-square-errors, mean-absolute-errors and coefficients of determination) are provided in Table SM2 for all simulations. The parameters for degradation kinetics $\left(v_{\max }, K_{M}, Y, b\right)$, and dissolution kinetics $\left(f_{A}\right)$ were determined iteratively for each bacterial strain until a combination was found that is optimal for all sets of experiments (initial nominal concentrations $10,25,50,100,200$ and $\left.400 \mathrm{mgL}^{-1}\right)$. Furthermore, lag phases (parameter $t_{\text {lag }}$ ) were adjusted individually for each experiment. In principle we followed the fitting procedure suggested by Adam et al. [5], i.e. first, the death rate constant $b$ was found from experiments with low initial substrate concentration, then $v_{\max }$ and $K_{M}$ were fitted, followed by the adjustment of $Y$, with subsequent re-iterations to improve the curve fits.

\section{Results}

The results for $M$. rutilum PHE and PYR degradation with measured versus modeled suspension concentration $C_{\text {Sus }}$ and estimated versus modeled microbial protein 
concentration $C_{X, \text { est }}$, are shown in figures 1 and 2 . The input data and the parameters obtained for growth and degradation of the strains are summarized in Table 2. PHE and PYR were degraded virtually completely at all initial concentrations $(10,25,50,100,200$, and $400 \cdot \mathrm{mgL}^{-1}$ ) within $\mathrm{t}<4 \mathrm{~d}$ for initial $\mathrm{C}_{\text {Sus }} \leq 100 \cdot \mathrm{mgL}^{-1}$ and $\mathrm{t}=8-12 \mathrm{~d}$ for initial $\mathrm{C}_{\text {Sus }} \geq 100 \cdot \mathrm{mgL}^{-1}$ in the fitted curves. Bacterial growth was observed at the first 0.5-2 days and was higher at higher initial substrate concentration. Depletion of substrate led to reduced growth and later decay. The simulations were performed with the same half-saturation constants $K_{M}$ for all strains (Table 2, 0.1· $\mathrm{mgL}^{-1}$ ) and succeeded in most cases.

227 Kinetic parameters for growth of $M$. rutilum on PHE were found as follows: $v_{\max }=10$ (range 7-12) $\mathrm{g} \cdot \mathrm{g}^{-1} \cdot$ bact $\cdot \mathrm{d}^{-1}, K_{M}=0.1 \cdot \mathrm{mgL}^{-1}, \quad b=0.03 \mathrm{~d}^{-1}, \quad Y=0.2$ (range 0.16-0.28) g.bact $\cdot \mathrm{g}^{-1}$. Numbers are best estimate values, with ranges (minimum to maximum estimates) in brackets. Lag phases for the experiments ranged from 0.1- 0.3 days (Table SM1).

231 The yield $Y$ for growth of $M$. rutilum on PYR was relatively similar as for growth on PHE, with 232 a best estimate of $0.22 \mathrm{~g} \cdot \mathrm{bact} \cdot \mathrm{g}^{-1}$, and the best estimate for $v_{\max }$ is $9 \mathrm{~g} \cdot \mathrm{g}^{-1} \cdot \mathrm{bact} \cdot \mathrm{d}^{-1}$ (range 7 -

233 11). The simulation succeeded with the same values for $K_{M}$ of $0.1 \cdot \mathrm{mgL}^{-1}$ and $b$ of $0.03 \mathrm{~d}^{-1}$. 234 Fitted lag phases ( $t_{\text {lag }}$ ) range from 0-0.8 days (Table SM1). Growth and substrate 235 consumption in these experiments are closely related and decline at the same time (Figures 236 SM2 and SM3).

237 For $M$. pallens growing on PYR (Figs. SM4 and SM5), the yield ( $Y=0.32 \mathrm{~g} \cdot \mathrm{bact}^{\mathrm{g}} \mathrm{g}^{-1}$ as best 238 estimate; Table 2) is higher than for M. rutilum growing on PYR, whereas $v_{\max }$ is similar with $2398 \mathrm{~g} \cdot \mathrm{g}^{-1} \cdot$ bact $\cdot \mathrm{d}^{-1}$ as best estimate (range $6-10 \mathrm{~g} \cdot \mathrm{g}^{-1} \cdot$ bact $\cdot \mathrm{d}^{-1}$ ). M. pallens showed a lower death 240 rate $b\left(0.01 \mathrm{~d}^{-1}\right)$ and the same $K_{M}$ (Table 2) but a longer lag phase (Table SM1) compared to 241 M. rutilum on PYR.

\section{Discussion}


PHE and PYR were degraded by the tested Mycobacterium strains at all initial concentrations accompanied by growth and subsequent decay after substrate consumption. Kinetic data $\left(v_{\max }, \mathrm{K}_{\mathrm{M}}\right.$ and $\left.Y\right)$ were obtained by non-linear fit of a Monod-type model. The non-linear fit gave similar maximum metabolic turnover rates for growth of $M$. rutilum and $M$. pallens on PYR. The yields and the decay rates differed slightly. $v_{\max }$ for growth on PYR is slightly lower than for growth on PHE, but the yields are higher. The likely ranges overlap and the differences might therefore not be significant. The lag phase for growth on PYR for M. rutilum was slightly longer than with $\mathrm{PHE}$ as substrate but the difference is insignificant ( $\mathrm{P}$ $>0.5$, paired t-test, two-tailed), while the lag phase of $M$. pallens with growth on PYR is clearly longer than that of $M$. rutilum $(P=0.057)$.

Earlier data obtained for growth of three bacterial strains on PHE in the same set-up gave higher results for the maximum metabolism rate $v_{\max }$ : Adam et al. [5] determined $v_{\max }$ values between 12 and $18 \mathrm{~g} \cdot \mathrm{g}^{-1} \cdot \mathrm{bact}^{-\mathrm{d}^{-1}}$ for the strains Novosphingobium pentaromativorans, Sphingomonas sp. EPA505 and Sphingobium yanoikuyae. The microbial yield was similar with $0.21 \mathrm{~g} \cdot \mathrm{g}^{-1}$ in the earlier study. Values for the half-saturation constant $K_{\mathrm{M}}$ show no difference $\left(K_{\mathrm{M}}=0.1 \cdot \mathrm{mg} / \mathrm{L}\right.$ in all cases) but this parameter is rather insensitive and other values would hardly alter the fit. The bacterial decay rate constant was slightly lower for the mycobacteria, with $b=0.01-0.03 d^{-1}$ compared to $b=0.04-0.05 d^{-1}$ found for Gram-negative degraders.

The estimates of $v_{\max }$ for the Mycobacterium species growing on PHE or Pyr carry substantial uncertainty: The measurement of microbial protein concentrations of Mycobacterium sp. provided difficulties. Direct measurement of microbial protein gave highly variable and nonplausible values. Optical density was used instead, and the effect of PAH on OD had to be subtracted (SM Section 1). Mycobacteria exhibit a pronounced cell cycle and tend to grow attached to the surface of the PAH crystals [13], and this may be the explanation for the considerable scatter and uncertainty in the estimated microbial protein concentration data. 
This attachment may also lead to slower dissolution of the PAH crystals, due to less contact

271 between aqueous phase and crystals.

272 Wick et al. [13] used solid anthracene as growth substrate for Mycobacterium sp. LB501T.

273 They obtained yields $\mathrm{Y}$ between 0.158 and $0.196 \mathrm{~g} \cdot$ biomass $\cdot \mathrm{g}^{-1} \cdot$ substrate $\cdot \mathrm{d}^{-1}$. The decay rate $274 b$ was determined to $0.017 \mathrm{~d}^{-1}$ from zero-growth and to $0.048 \mathrm{~d}^{-1}$ from nonlinear fit, $K_{M}$ was $275 \quad 0.0428 \cdot \mathrm{mgL}^{-1}$ and the maximum metabolic rate $v_{\max }$ was $18.4 \mathrm{~g} \cdot$ substrate $^{-1} \mathrm{~g}^{-1} \cdot \mathrm{biomass} \cdot \mathrm{d}^{-1}$. The 276 estimated $v_{\max }$ is higher than the values obtained in our study but was accompanied by lower 277 yields. Maximum growth rates $\mu_{\max }$ are obtained by $v_{\max } \times \cdot Y$. The $\mu_{\max }$ for the mycobacteria 278 ranged from 1.98 to $2.56 \mathrm{~d}^{-1}$ and were thus lower than those obtained by Adam et al. [5] 279 (2.52-3.78 $\left.\mathrm{d}^{-1}\right)$ and Wick et al. [13] (2.9-3.59 $\left.\mathrm{d}^{-1}\right)$. A relation to water solubility could not be 280 established, the water solubility of anthracene is $0.048 \cdot \mathrm{mg} / \mathrm{L}$, of PHE $1.15 \cdot \mathrm{mgL}^{-1}$, and of PYR $281 \quad 0.135 \cdot \mathrm{mgL}^{-1}[18]$.

Modeled substrate concentrations yielded predominantly good estimations with coefficients of determination $\mathrm{R}^{2}$ above 0.95 in most cases. Curve fits for microbial protein concentration $C_{X}$ were generally less satisfying than those for substrate concentration (Tab. SM2). This can be attributed to uncertainties associated with the determination of $C_{X}$ from optical density measurements (as discussed above) and the scattered results. The $R^{2}$-values obtained show strong variations between individual experiments, predominantly ranging between 0.41 and 0.94. Estimations are often better at higher initial substrate concentration. In some cases $C_{X}$ decreased during the lag phase, before microbes start to grow (within the first 0.2 to 0.5 days, e.g. Fig. 1a to d). Since the model does not consider specific processes during the lag phase but simply sets growth to zero, deviations to measurements occurred. The lowest $R^{2}$ (0.056, Tab. SM2) was obtained for the fit of the M. rutilum biomass $C_{X}$ at the lowest dose of PHE (Fig. 1a), where the fit is impacted by a very high $C_{X}$ at $\mathrm{t}=0.5 \mathrm{~d}$. 
Sorption processes to solid matter and dissolution from NAPLs are limiting the mass transfer and are causing residual non-degradable concentrations in real contaminated sites [12]. As stated previously [5], the model assumes that transport and bacterial uptake of compounds occurs via the water phase. Even for the mycobacteria no indication was found that transport may also be enabled directly from the organic phase/crystal to the cell surface plus membrane and the transfer and turnover processes can sufficiently be described without considering direct transfer. Considering direct uptake from crystals or NAPLs in the model would not change the kinetics, because in all cases the driver for uptake and metabolism is the chemical activity in solution (maximum activity = water solubility). This is at the same time the activity of the pure solid phase in contact to water [19]. The flux of the substrate to the microbes is the limiting factor. Increasing the dissolution kinetics and the flux to their enzymes by various means, e.g. increase of the surface of mobilization by exudates acting as solvents or biosurfactants or by altering their cell surface properties is therefore a more promising strategy for bacteria than metabolizing solid or NAPL phase substrate directly [5]. The effect of these strategies may be larger if the microbes grow in direct contact to the crystals.

\subsection{Sorption and mass transfer.}

$\mathrm{PAH}$ at real contaminated sites are mixed contaminations in a tar oil matrix in most cases and the partitioning equilibrium of single compounds between the tar oil and the water phase are determined by the chemical activity of each compound in the oil matrix expressed by the Raoult's law; $\mathrm{K}_{\mathrm{d}}$ or $\mathrm{K}_{\mathrm{oc}}$ values of $\mathrm{PAH}$ determined in short-term laboratory experiments are not representing the situation in real contaminated soils with or without ongoing degradation. The apparent $K_{d}$ values in such soils (i.e. the concentration ratio between adsorbed/sequestered and freely dissolved molecules) are not constant, since $K_{d}$ increases with time due to sequestration or aging (Figures $3 a, 3 d$ ) [10]. In addition, the apparent $K_{d}$ increases due to bacterial degradation, which lowers primarily the concentration in dissolved state as long as degradation is ongoing. For the often observed persistence of the 
compounds in real environmental systems, increasing half-lives may be due to less substrate present in the dissolved phase. The often postulated irreversible sorption [20] is not required to explain the phenomenon of environmental persistence. After long periods of aging at real contaminated sites, the slow desorption flux of $\mathrm{PAH}$ from the sequestered or from the residual tar oil fraction is the only remaining source of compound and limits bacterial growth and metabolism.

\subsection{Limitations of growth.}

In general, not only the carbon source but also nutrients may limit growth [21]. Moreover, growth strongly depends on substrate flux and chemical activity of the compounds. By setting $\mathrm{dX} / \mathrm{dt}$ (Eq. 3) to zero, the minimum chemical activity a (truly dissolved concentration in aqueous phase) for growth of degraders on the substrate can be calculated:

$a_{\text {nogrowth }}=\frac{b \times K_{M}}{\mu_{\max }-b}$

The resulting minimum activity is $1.5 \cdot \mathrm{\mu gL}^{-1}(8.5 \mathrm{nM})$ for mycobacteria on $\mathrm{PHE}$, and $0.4-1.5 \cdot \mu \mathrm{g}$ $\mathrm{L}^{-1}(2-8 \mathrm{nM})$ on PYR. The values are surprisingly similar to those found for growth of Grampositive strains on PHE (6 to $11 \mathrm{nM}$ PHE) [5]. All results are sufficiently far below water solubility and strains grow on PHE and PYR. However, the water solubility of the higher molecular PAH, such as benzo(a)pyrene, chrysene, indeno(1,2,3-cd)pyrene, and dibenz[a,h]anthracene, is lower. If the degrader strains metabolize the higher molecular weight PAH with the same efficiency (i.e. the same kinetic data) as found for PHE and PYR, their use as sole growth substrate is then limited, as shown in previous experiments [6]. The water solubility of benzo(a)pyrene is at $4.5 \mu \mathrm{gL}^{-1}(18 \mathrm{nM})$, that of dibenz[a,h]anthracene at $2.5 \cdot \mathrm{\mu gL}^{-1}$ (9 $\mathrm{nM})$, and that of indeno(1,2,3-cd)pyrene only at $0.5 \cdot \mu \mathrm{gL}^{-1}(1.8 \mathrm{nM})$ [18]. This means that even if the pure substance is present in neighborhood to an aqueous phase, the solubility is almost too low to support bacterial growth on these substances. The only way for biodegradation is then co-metabolism, i.e. growth of degrader strains on another, more 
soluble substrate. This is not based on the genetic or enzymatic potential of the degrading bacteria, but on dissolution kinetics and water solubility which limit the $\mathrm{PAH}$ flux towards the cells.

\subsection{Modification of the model approach for simulation of aging in soils and sediments.}

The ultimate goal of the model development was to provide a tool for simulating remediation options for PAH contaminated sites. Desorption of aged PAH from soils and sediments can be described by a bi-phase kinetics, with a fast and a slow desorption rate, as suggested by Johnson et al. [22]. We therefore replaced the dissolution term for PAH crystals (eq. 1) with a rapid ad/desorption to soil and a slow sequestration/remobilization step following in series:

$\frac{d m_{D}}{d t}=-k_{D A} m_{D}+k_{A D} m_{A}-\frac{d m_{M}}{d t}+$ source

$$
\frac{d m_{A}}{d t}=+k_{D A} m_{D}-k_{A D} m_{A}+k_{S A} m_{S}-k_{A S} m_{A}
$$

$$
\frac{d m_{S}}{d t}=+k_{A S} m_{A}-k_{S A} m_{S}
$$

where $D$ is the index for the mass of substance in the truly dissolved phase (synonymous to W water phase in eq. 1, 2 and 4), $A$ is for adsorbed phase (rapid) and $S$ is for sequestration (slow). The model was parameterized for $\operatorname{PHE}\left(\mathrm{K}_{\mathrm{d}}=162 \mathrm{Lkg}^{-1}\right)$, the exchange rates $\mathrm{k}$ were set to $\mathrm{k}_{\mathrm{AD}}=0.09 \mathrm{~d}^{-1}$ and $\mathrm{k}_{\mathrm{SA}}=1.73 \times 10^{-3} \mathrm{~d}^{-1}$ [23], and are within the range given by Johnson et al. [22]. The backward rates are these values multiplied with $\mathrm{K}_{\mathrm{d}}$.

\subsection{Simulations of remediation options.}

The unified model [24] for mass transfer, sorption, sequestration and metabolism was also applied for the simulation of typical scenarios and remediation options.

In the first scenario, representing a typical fresh contamination of a soil, the source of PAH is an oil phase with $1 \mathrm{~g}$ PHE distributed evenly over a volume of $1 \mathrm{~m}^{3}$. PHE dissolves within a 
few days into the dissolved phase (D), from where rapid adsorption (A) and subsequent sequestration take place (Fig. 3a). A degrader population with kinetic data of Sphingobium yanoikuyae $\left(Y=0.21 \mathrm{~g} \cdot \mathrm{g}^{-1}, v_{\max }=18 \mathrm{~g} \cdot \mathrm{g}^{-1} \cdot \mathrm{d}^{-1}\right)$ [5], i.e. the most efficient strain tested in previous experiments [5], grows vividly until the substrate in D and then also in A is depleted and then declines. The remaining substrate ends up in almost equal parts in $A$ and $S$. Despite sufficient substrate present for further growth, it is not available for the degrader population, and the PAH in soil is "aged" and persists (Fig. 3a).

Starting from a soil with aged contamination, e.g. an aged contaminated site with NAPL, coal and coke material (the outcome of simulation 1) with a PHE residual mass in $1 \mathrm{~m}^{3}$ soil of $0.08 \mathrm{~g}, 61 \%$ hereof in S, $39 \%$ in $A$ and $0.2 \%$ in $D$, and initial microbial biomass $X(0)=7 \times 10^{-}$ ${ }^{4} \cdot \mathrm{gm}^{-3}$, several remediation options were simulated. Bioaugmentation is simulated by the addition of degrader bacteria $\left(X=0.05 \mathrm{gm}^{-3}\right)$ after 2 years $(t=730 \mathrm{~d})$ (Figure $\left.3 \mathrm{~b}\right)$. An effect is visible as a reduction of $A$ and $D$ (the "bioavailable" fraction), but the change is small and rarely affects the sequestered substrate in S. Within short time, the bacterial population declines again. This scenario may be the background for many failed bioremediation approaches in real contaminated sites. Unfortunately, most of these reports are only published in the 'grey' literature about remediation actions; nevertheless, some of them are also mentioned in peer-reviewed literature [25, 26].

An alternative strategy is the addition of adsorbing amendments to soil [27, 28], which we simulated by a ten-fold increased organic carbon content of the soil, equivalent to a ten-fold increase of $\mathbf{K}_{d}$ (Fig. 3c). Practically all substrate remains present adsorbed (A) or sequestered $(S)$ and bacterial degraders $\mathrm{X}$ decline further. The $\mathrm{PAH}$ exposure and toxicity may be reduced by this measure, but the biodegradation is not stimulated. This scenario is presumably realised in many contaminated sites of former gas work sites, in which particulate waste coal and coke materials were added for solidification of waste liquid coal tars finally resulting in non-bioavailable and non-degradable residual concentrations [9]. 
The opposite strategy of increasing the dissolution (decrease of desorption rate $K_{d}$ ) is simulated by taking 10 fold less organic carbon into account. Reduced adsorption can be achieved in practice by the addition solvents or chelators. Increased solubility stimulates bacterial degradation (Fig. 3d), substrate is removed from D and A, and subsequently also the sequestered pool declines. This scenario was realised by addition of surfactants in particular, using alcohol ethoxylates or glycoside-based surfactants that are found to improve the $\mathrm{PAH}$ degradation [29, 30], or by organic solvents such as acetone [31]. However, higher dissolved concentrations of $\mathrm{PAH}$ might result in higher toxicity.

The last scenario is co-metabolism, and it is simulated with a constant (and high) bacterial biomass $X$ of $0.01 \mathrm{~g} \cdot \mathrm{m}^{-3}$ (Fig. 3e). In the long run, this seems the most successful bioremediation strategy, because it leads to a constant and steady decline of PAH in all pools. This scenario may explain the increase of $\mathrm{PAH}$ after compost addition to soil $[27,28$, 32, 33].

\section{Conclusions}

Highly sorptive materials, e.g. black carbon (BC) materials and NAPLs like tar or mineral oils, are often found in contaminated gas work sites [9]. Tar oils are hydrophobic NAPLs like crude oil and contain various amounts of PAH. Raoult's law was shown to determine the chemical activity and thereby the mass transfer of each compound from the NAPL to the water phase according to the molar fraction of each compound in the tar oil [3, 34-38]. After decades of being dumped in the subsurface the majority of the tar oil residues are biodegraded except of those being associated to coal and coke particles [9]. Due to the degradation of low molecular weight compounds in aged tar oil NAPLs and the enrichment of amphiphilic molecules at the NAPL water interphase, the viscosity of the interface between the remaining tar oil and the water may increase. This results in an additional decrease of the mass transfer from the NAPL to the water phase. The contamination history and the structure 
422 and composition of the soil material thus determine the outcome of bioremediation

423 treatments. In the real world temperature and soil water content also modify the degradation

424 rates [12].

425 The simulations offer distinct prospective power for the assessment of remediation options of

426 contaminated soils. At aged sites, degrader strains cannot grow due to limited substrate

427 availability and thus the effect of their addition (bioaugmentation) is marginal and short-

428 termed. Moreover, a high abundance of $\mathrm{PAH}$ degrader communities in practically all

429 investigated soils - including pristine soils - has been confirmed for naphthalene and PHE [8].

430 It can be concluded that amendment with degrader bacteria is not stimulating $\mathrm{PAH}$

431 degradation significantly over extended time spans in most cases. The addition of sorbents

432 like biochar may decrease the bioavailable fraction and thus lower plant uptake and

433 toxicological risk but will increase the persistence of the residual fraction due to a very limited

434 substrate availability. Desorption flux can be stimulated by solvents (e.g. acetone) or

435 surfactants (in best case those that can be used as substrate by the bacteria), which,

436 however, also increases toxicity and risk of leaching. Bacterial growth can also be stimulated

437 with complex co-substrates (compost, root exudates) enhancing co-metabolism and the

438 bioavailability of sorbed PAH and resulting in a long-term increase of PAH degradation rates.

Supporting Material

Additional information noted in the text is available.

Conflict of interest

445 The authors declare no competing financial interest. 
448 This research Project was financially supported by the European Union (Project "Molecular 449 Approaches and MetaGenomic Investigations for optimizing Clean-up of PAH contaminated 450 sites, MAGICPAH, Grant Agreement No. 245226) and by the Helmholtz Centre for 451 Environmental Research UFZ. The unified model with description is available in a public 452 version at http://www.magicpah.org/links/ or http://homepage.env.dtu.dk/stt/. We also thank 453 reviewer 2 for valuable comments to improve the manuscript. 


\section{References}

457 [1] H.J. Hassett, W.L. Banwart, The sorption of nonpolar organics by soils and sediments, in:

458 B.L. Sahwney, K. Brown (Eds.) Reactions and Movement of organic chemicals in soils, 459 SSSA Special Publication No. 22, Soil Science Society of America, American Society of 460 Agronomy, Madison, Wisconsin, USA, 1989.

[2] P.G. Wislocki, A.Y.H. Lu, Carcinogenicity and mutagenicity of proximate and ultimate carcinogens of polycyclic aromatic hydrocarbons, in: S.K. Yang, B.D. Silverman (Eds.) Polycyclic aromatic hydrocarbon carcinogenesis: structure-activity relationships, CRC-Press, Boca Raton, 1988, pp. 1-30.

[3] M. Kästner, Degradation of aromatic and polyaromatic compounds, in: H.-J. Rehm, G. Reed, A. Pühler, P. Stadler (Eds.) Biotechnology, 2nd Edition, Vol. 11b; Environmental Processes, Wiley-VCH, Weinheim, 2000, pp. 211-239.

[4] C.E. Cerniglia, M.A. Heitkamp, Microbial metabolism of polycyclic aromatic hydrocarbons $(\mathrm{PAH})$ in the aquatic environment, in: U. Varanasi (Ed.) Metabolism of polycyclic aromatic hydrocarbons in the aquatic environment, CRC Press, Boca Raton, 1989, pp. 41-68.

[5] I.K.U. Adam, A. Rein, A. Miltner, A.C. da Costa Fulgêncio, S. Trapp, M. Kästner,

472 Experimental results and integrated modeling of bacterial growth on an insoluble hydrophobic substrate (phenanthrene), Environ. Sci. Technol., 48 (2014) 8717-8726. [6] R.A. Kanaly, S. Harayama, Advances in the field of high-molecular-weight polycyclic aromatic hydrocarbon biodegradation by bacteria, Microb Biotechnol, 30 (2010) 136-164.

476 [7] A. Bjørseth, T. Ramdahl, Sources and emissions of PAH, in: A. Bjørseth, T. Ramdahl

477 (Eds.) Handbook of polycyclic aromatic hydrocarbons, Marcel Dekker, New York, 1985, pp. $478 \quad 1-20$.

479 [8] A.R. Johnsen, U. Karlson, PAH degradation capacity of soil microbial communities - Does 480 it depend on PAH exposure?, Microb. Ecol., 50 (2005) 488-495. 
481 [9] U. Wiesmann, Der Steinkohleteer und seine Destillationsprodukte - Ein Beitrag zur

482 Geschichte der Technik und der Bodenverschmutzung, in: B. Wiegert (Ed.) Biologischer

483

484

485

486

487

488

489

490

491

492

493

494

495

496

497

498

499

500

501

502

503

504

505

506

507

Abbau von polyzyklischen aromatischen Kohlenwasserstoffen, SFB 193, TU Berlin, Berlin, 1994, pp. 3-18.

[10] M. Alexander, Aging, bioavailability, and overestimation of risk from environmental pollutants, Environ. Sci. Technol., 34 (2000) 4259-4265.

[11] K.J. Doick, E. Klingelmann, P. Burauel, K.C. Jones, K.T. Semple, Long-term fate of polychlorinated biphenyls and polcyclic aromatic hydrocarbons in an agricultural soil, Environ. Sci. Technol., 39 (2005) 3663-3670.

[12] M. Kästner, K.M. Nowak, A. Miltner, S. Trapp, A. Schäffer, Classification and modelling of non-extractable residue (NER) formation of xenobiotics in soil - a synthesis, Crit. Rev. Environ. Sci. Technol., 44 (2014) 2107-2171.

[13] L.Y. Wick, T. Colangelo, H. Harms, Kinetics of mass transfer-limited bacterial growth on solid PAHs, Environ. Sci. Technol., 35 (2001) 354-361.

[14] C.T. Hennessee, J.S. Seo, A.M. Alvarez, Q.X. Li, Polycyclic aromatic hydrocarbondegrading species isolated from Hawaiian soils: Mycobacterium crocinum sp. nov., Mycobacterium pallens sp. nov., Mycobacterium rutilum sp. nov. and Mycobacterium aromaticivorans sp.nov., Int. J. Syst. Evol. Microbiol., 59 (2009) 378-387.

[15] DSMZ, Mineral Medium (Brunner) with Vitamins, in, 2010.

[16] I.N. Bronstein, K.A. Semendyayev, G. Musiol, H. Muehlig, Handbook of Mathematics, 7th German ed., Verlag Harri Deutsch, Frankfurt/Main, 2008.

[17] I.K.U. Adam, A. Rein, A. Miltner, A.C. da Costa Fulgêncio, S. Trapp, M. Kästner, Experimental results and integrated modeling of bacterial growth on an insoluble hydrophobic substrate (phenanthrene). Environmental Science \& Technology, 48 (2014) 8717-8726.

[18] G. Rippen, Handbuch Umweltchemikalien - Stoffdaten - Prüfverfahren - Vorschriften, ecomed Verlagsgesellschaft, Landsberg am Lech, 1990. 
[19] S. Trapp, A. Franco, D. Mackay, Activity-based concept for transport and partitioning of ionizing organics, Environ. Sci. Technol., 44 (2010) 6123-6129, incl. Supporting Information. [20] J.J. Pignatello, B.S. Xing, Mechanisms of slow sorption of organic chemicals to natural particles, Environ. Sci. Technol., 30 (1996) 1-11.

[21] D.K. Button, Kinetics of nutrient-limited transport and microbial growth, Microbiol. Rev., 49 (1985) 270-297.

[22] M.D. Johnson, T.M. Keinath, W.J. Weber, A distributed reactivity model for sorption by sails and sediments. 14. Characterization and modeling of phenanthrene desorption rates, Environ. Sci. Technol., 35 (2001) 1688-1695.

[23] S. Trapp, M. Kästner, I.K.U. Adam, A. Rein, U. Gosewinkel Karlson, Methods for improvement of PAH degradation by substrate amendments, solvent and phytoremediation, in, Project Molecular Approaches and Metagenomic Investigations for Optimizing Clean-up of PAH-contaminated Sites (MagicPAH), EU FP 7 KBBE-2009-3-5-01, Deliverable 36, 2014.

[24] S. Trapp, A. Rein, Predictive model for PAH degradation and residue formation related to bioavailability, in, Project Molecular Approaches and Metagenomic Investigations for Optimizing Clean-up of PAH-contaminated Sites (MagicPAH), EU FP 7 KBBE-2009-3-5-01, Magic PAH Deliverable 23, available at http://homepage.env.dtu.dk/stt/Magic\%20PAH/Magic\%20PAH\%20Deliverable\%2023.pdf, last retrieved 13 May 2015, 2012.

[25] C. García-Delgado, A. D’Annibale, L. Pesciaroli, F. Yunta, S. Crognale, M. Petruccioli, E. Eymar, Implications of polluted soil biostimulation and bioaugmentation with spent mushroom substrate (Agaricus bisporus) on themicrobial community and polycyclic aromatic hydrocarbons biodegradation., Science of the Total Environment 508 (2015) 20-28. [26] N. Loick, P.J. Hobbs, M.C.D. Hale, D.L. Jones, Bioremediation of Poly-Aromatic Hyrdocarbon (PAH)-Contaminated Soil by Composting., Crit. Rev. Environ. Sci. Technol., 39 (2012) 271-332. 
[27] G. Marchal, K.E.C. Smith, A. Rein, A. Winding, L.W. de Jonge, S. Trapp, U.G. Karlson,

535

536

537

538

539

540

541

542

543

544

545

546

547

548

549

550

551

552

553

554

555

556

557

558

559

560

561 Impact of activated carbon, biochar and compost on the desorption and mineralization of phenenthrene in soil, Environ. Pollut., 181 (2013) 200-210.

[28] G. Marchal, K.E.C. Smith, A. Rein, A. Winding, S. Trapp, U.G. Karlson, Comparing the desorption and biodegradation of low concentrations of phenanthrene sorbed to activated carbon, biochar and compost, Chemosphere, 90 (2013) 1767-1778.

[29] T. Madsen, P. Kristensen, Effects of bacterial inoculation and nonionic surfactants on degradation of polycyclic aromatic hydrocarbons in soil., Environmental Toxicology and Chemistry, 16 ( 1997) 631-637.

[30] M. Megharaj, B. Ramakrishnan, K. Venkateswarlu, N. Sethunathan, R. Naidu, Bioremediation approaches for organic pollutants: A critical perspective., Environmental International, 37 (2011) 1362-1375.

[31] T. Grotenhuis, J. Field, R. Wasseveld, W. Rulkens, Biodegradation of polyaromatic hydrocarbons (PAH) in polluted soil by the white-rot fungus Bjerkandera., Journal of Chemical Technology and Biotechnology, 71 (1999) 359-360.

[32] I.K.U. Adam, A. Miltner, M. Kästner, Degradation of ${ }^{13} \mathrm{C}$-labelled pyrene degradation in soil-compost mixtures and fertilized soil, Appl. Microbiol. Biotechnol., (2015) in press.

[33] M. Kästner, B. Mahro, Microbial degradation of polycyclic aromatic hydrocarbons in soils affected by the organic matrix of compost, Appl. Microbiol. Biotechnol., 44 (1996) 668-675. [34] C. Eberhardt, P. Grathwohl, Time scales of organic contaminant dissolution from complex source zones: coal tar vs. blobs, J. Contam. Hydrol., 59 (2002) 45-66.

[35] S. Ghoshal, A. Ramaswami, R.G. Luthy, Biodegradation of naphthalene from coal tar and heptamethylnonane in mixed batch systems, Environ. Sci. Technol., 30 (1996) 12821291.

[36] L.S. Lee, M. Hagwall, J.J. Delfino, P.S.C. Rao, Partitioning of polycyclic aromatic hydrocarbons from Diesel fuel into water, Environ. Sci. Technol., 26 (1992) 2104-2110. [37] L.S. Lee, P.S.C. Rao, I. Okuda, Equilibirum partitioning of polycyclic aromatic hydrocarbons from coal tar into water, Environ. Sci. Technol., 26 (1992) 2110-2115. 
562 [38] M. Wehrer, T. Rennert, K.-U. Totsche, Kinetic control of contaminant release from

563 NAPLs - Experimental evidence, Environ. Pollut., 179 (2013) 315-325.

564 [39] Metcalf, Eddy, Wastewater Engineering, Treatment and Reuse, Mc-Graw Hill, New York, 5652003.

566

567 


\section{Figure captions}

569

570

571

572

573

574

575

576

577

578

579

580

581

582

583

584

585

586

587

588

589

590

591

592

593

594

Figure 1. Experiments with Mycobacterium rutilum: PHE concentration in suspension $C_{\text {Sus }}$ $(-\rightarrow)$ and estimated microbial protein concentration $C_{X, \text { est }}(-\cdot-\circ-\cdot-)$, measured (data points) versus modeled (curves). Experiments with nominal initial phenanthrene concentrations: a) $C_{0}=10 \mathrm{mgL}^{-1}$, b) $C_{0}=25 \mathrm{mgL}^{-1}$, c) $C_{0}=50 \mathrm{mgL}^{-1}$, d) $C_{0}=100 \mathrm{mgL}^{-1}$, e) $C_{0}=200 \mathrm{mgL}^{-1}$, f) $C_{0}$ $=400 \mathrm{mgL}^{-1}$. Error bars indicate minimum and maximum (3 replicates).

Figure 2. Experiments with Mycobacterium rutilum: PYR concentration in suspension $C_{\text {Sus }}$ $(-\rightarrow)$ and estimated microbial protein concentration $C_{X, \text { est }}(-\cdot-\circ-\cdot-)$, measured (data points) versus modeled (curves). Experiments with nominal initial pyrene concentrations: a) $C_{0}=10$ $\mathrm{mgL}^{-1}$, b) $C_{0}=25 \mathrm{mgL}^{-1}$, c) $C_{0}=50 \mathrm{mgL}^{-1}$, d) $C_{0}=100 \mathrm{mgL}^{-1}$, e) $C_{0}=200 \mathrm{mgL}^{-1}$, f) $C_{0}=400$ $\mathrm{mgL}^{-1}$. Error bars indicate minimum and maximum (3 replicates).

Figure 3. Simulation of remediation scenarios with the most efficient degrader strain Sphingobium yanoikuyae. Dissolved PHE phase (-), adsorbed PHE phase (---), sequestered PHE phase (- -), microbial protein (•••). a) Scenario after release of $1 \mathrm{~g}$ PHE into $1 \mathrm{~m}^{3}$ soil. This panel additionally shows PHE in the NAPL phase for the first 2.6. days (...). b) Bioaugmentation with microbial degrader biomass to $X=0.05 \mathrm{~g} / \mathrm{m}^{3}$ after 2 more years, c) Amendment with organic carbon ( $O C=20 \%, K_{d}$ increased by a factor of 10$)$, d) solubilisation ( $\mathrm{K}_{\mathrm{d}}$ decreased by a factor of 10$)$, e) simulation of co-metabolism with constant $X=0.01 \mathrm{~g} \cdot \mathrm{m}^{-3}$. 
595 Table 1. PHE and PYR degrading strains used in the present experiments

\begin{tabular}{lll}
\hline Species & Mycobacterium rutilum & Mycobacterium pallens \\
\hline DSM-No. & 45405 & 45404 \\
Gram staining & positive & positive \\
Morphology & rod-shaped & rod-shaped \\
Motility & - & - \\
Isolated from & soil from urban park in Honolulu, & non-contaminated soil from \\
& Hawaii, USA [14] & Wahiawa, Hawaii, USA [14] \\
PAH mineralization & PHE, PYR & PHE, FLU, PYR \\
\hline
\end{tabular}


strains

\begin{tabular}{lllll}
\hline Parameters & Symbol & Value & Unit & Reference / comment \\
\hline Input parameters & & & & \\
Suspension volume & $V_{\text {Sus }}$ & 0.1 & $\mathrm{~L}$ & \\
PHE density & $\rho_{p h}$ & 1100 & $\mathrm{~kg} \mathrm{~m}^{-3}$ & {$[18]$} \\
PYR density & $\rho_{p h}$ & 1270 & $\mathrm{~kg} \mathrm{~m}^{-3}$ & {$[18]$} \\
PHE water solubility & $S$ & 1.15 & $\mathrm{~g} \mathrm{~m}^{-3}$ & {$[18]$} \\
PYR water solubility & $S$ & 0.135 & $\mathrm{~g} \mathrm{~m}^{-3}$ & {$[18]$} \\
Microbial protein fract. & $f_{m, \text { prot }}$ & 0.55 & $\mathrm{~g} \mathrm{prot} \mathrm{g}^{-1}$ biomass & {$[39]$}
\end{tabular}

Fitted parameters - Dissolution flux

$\begin{array}{lllll}\text { PHE permeability } \times f_{A} & P \times f_{A} & 160(120-200) & \mathrm{m} \mathrm{d}^{-1} & \text { details see SM } \\ \text { PYR permeability } \times f_{A} & P \times f_{A} & 475(400-550) & \mathrm{m} \mathrm{d}^{-1} & \text { details see SM }\end{array}$

\section{Fitted parameters - Monod}

Mycobacterium rutilum and PHE degradation

$\begin{array}{llll}\text { Half-saturation const. } & K_{M} & 0.1 & \mathrm{~g} \mathrm{~m}^{-3} \\ \text { Yield } & Y & 0.20(0.16-0.28) & \mathrm{g} \mathrm{bact} \mathrm{g}^{-1} \\ \text { Death rate const. } & b & 0.03 & \mathrm{~d}^{-1} \\ \text { Max. removal rate } & v_{\max } & 10(7-12) & \mathrm{g} \mathrm{g}^{-1} \text { bact }^{-1}\end{array}$

Mycobacterium rutilum and PYR degradation

$\begin{array}{llll}\text { Half-saturation const. } & K_{M} & 0.1 & \mathrm{~g} \mathrm{~m}^{-3} \\ \text { Yield } & Y & 0.22(0.17-0.28) & \mathrm{g} \mathrm{bact} \mathrm{g}^{-1} \\ \text { Death rate const. } & b & 0.03 & \mathrm{~d}^{-1} \\ \text { Max. removal rate } & v_{\max } & 9(7-11) & \mathrm{g} \mathrm{g}^{-1} \text { bact d }^{-1}\end{array}$

Mycobacterium pallens and PYR degradation

$\begin{array}{llll}\text { Half-saturation const. } & K_{M} & 0.1 & \mathrm{~g} \mathrm{~m}^{-3} \\ \text { Yield } & Y & 0.32(0.25-0.36) & \mathrm{g} \mathrm{bact} \mathrm{g}^{-1} \\ \text { Death rate const. } & b & 0.01 & \mathrm{~d}^{-1} \\ \text { Max. removal rate } & v_{\max } & 8(6-10) & \mathrm{g} \mathrm{g}^{-1} \text { bact } \mathrm{d}^{-1}\end{array}$

(fitted parameters: best estimate values, with ranges in brackets; fract.: fraction; const.: constant; max.: maximal; corr.: correction, bact: bacteria; prot: protein; $\mathrm{f}_{\mathrm{A}}$ : correction factor for deviations of 
605

606
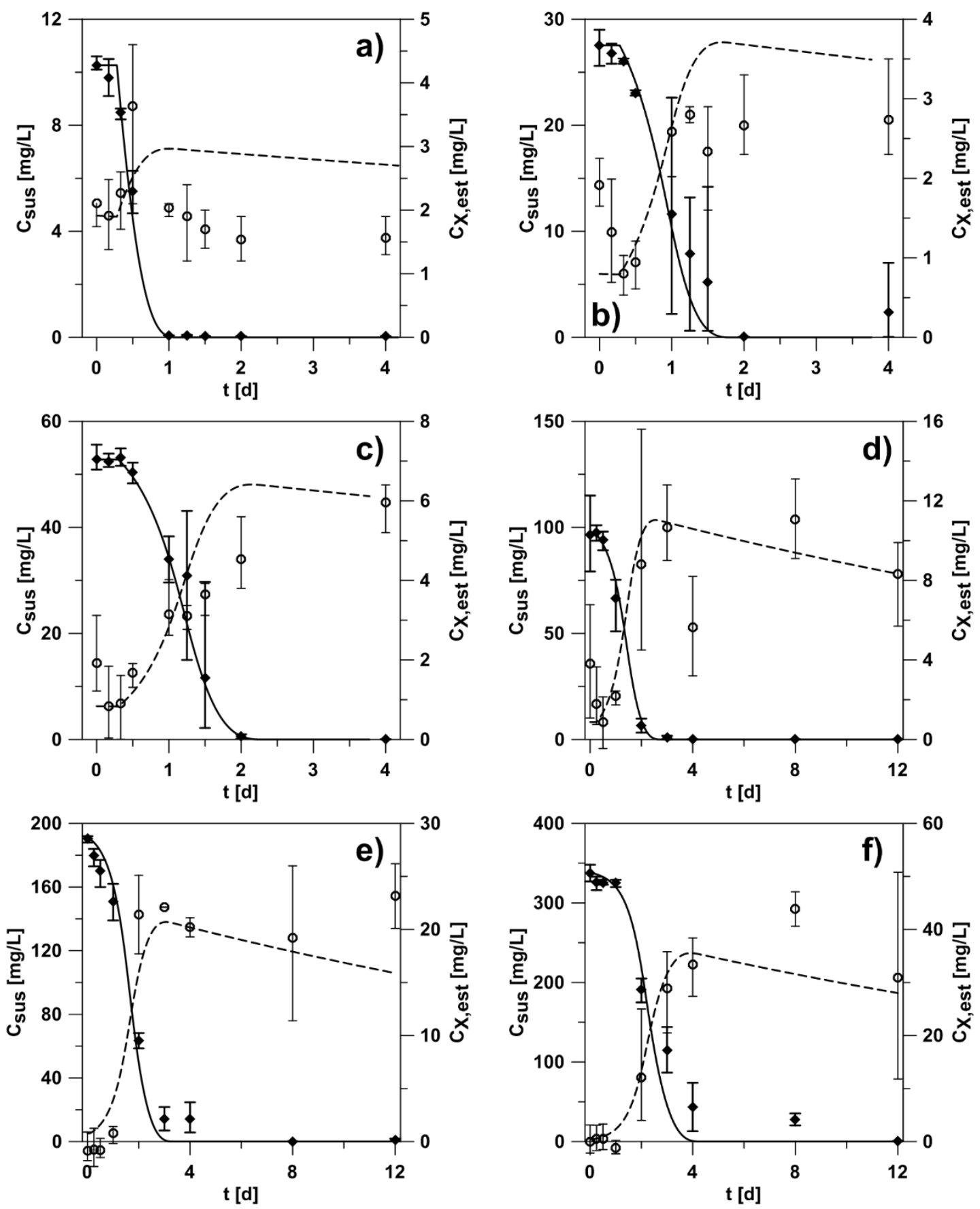

608

609

610

611

612

Figure 1
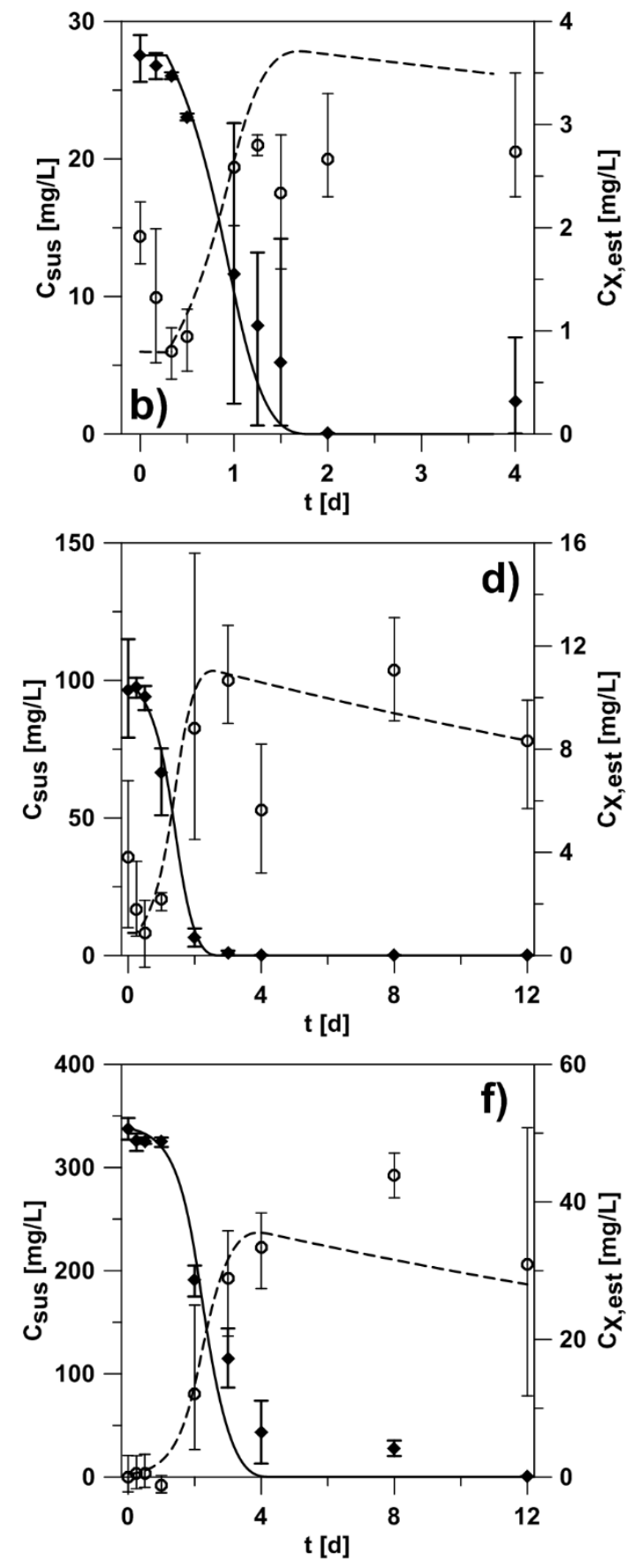

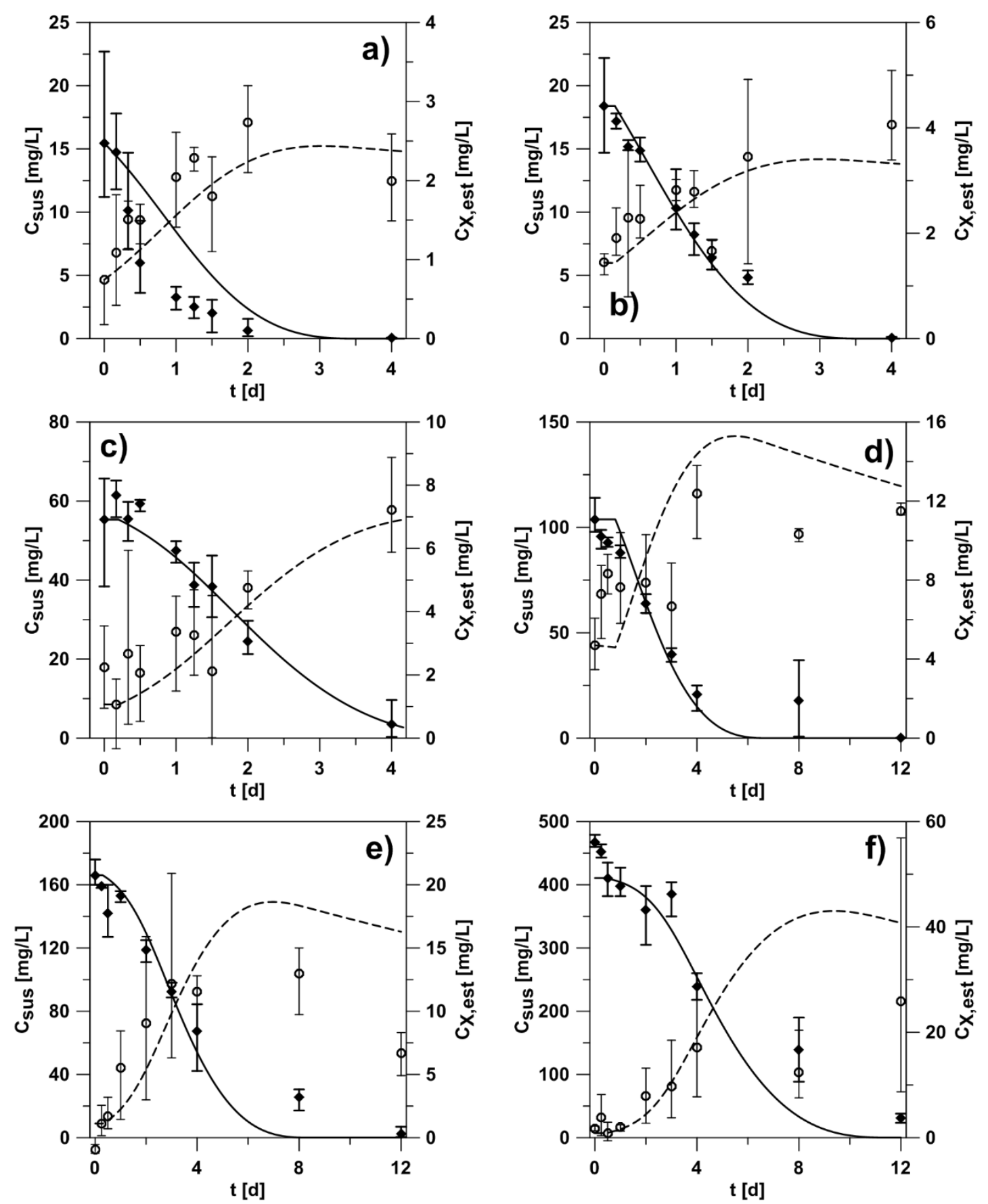

615

616

617

618

619

620

621

Figure 2 

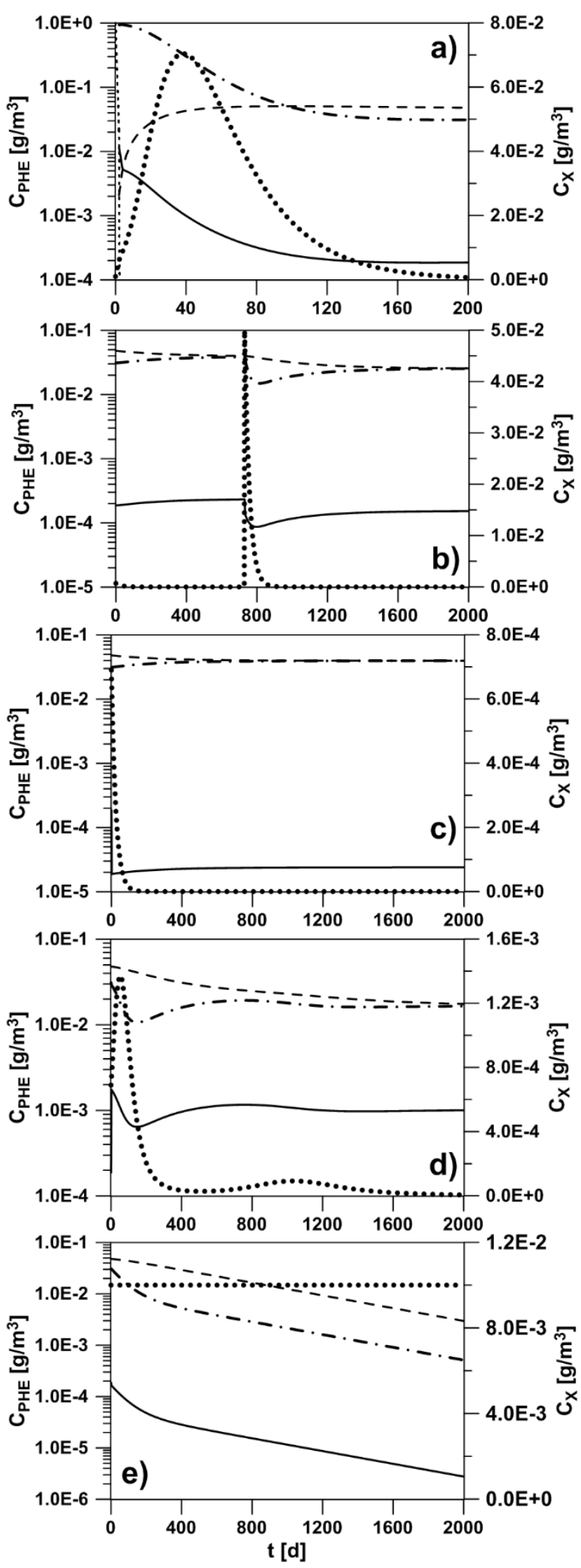